\title{
Borrowing and Code-switching as linguistic phenomena in a multilingual community: the case study of Baatonum (Bariba), French and English in the north-eastern border of Benin.
}

\author{
HAKIBOU Abdoulaye
}

\begin{abstract}
Résumé:- La république du Bénin et la république fédérale du Nigéria sont deux pays fortement multilingues. Ces deux pays frères de part la situation géographique sont tout aussi frères de par leurs peuples. Ils ont été colonisés par deux différents peuples européens, notamment et respectivement par les Français et les Anglais. Ce qui ajoute à la multitude de langues déjà existantes celle du colonisateur qui devient du fait la langue officielle avec un statut particulier. Ce statut particulier fait du Français la lingua franca au Bénin et l'Anglais la lingua franca au Nigéria, entre les différents groupes ethniques de ces pays. Aujourd'hui, l'usage du Français est devenu presque habituel entre les locuteurs Baatombu du Bénin come c'est le cas de l'Anglais pour les locuteurs Baatombu du Nigéria. Cela s'explique par la nature prestigieuse de ces deux langues dans le concert des langues de chacun de ces deux pays. La conséquence directe de cette cohabitation est l'influence mutuelle qui se traduit par une alternance codique que les interlocuteurs lettrés tentent de cacher derrière le phénomène linguistique appelé emprunt. L'alternance codique et l'emprunt sont deux phénomènes linguistiques ayant lieu suivant des conditions. La présente étude tente d'identifier les conditions dans lesquelles ils ont lieu en même temps qu'elle se propose de montrer celles qui conduisent les usagers à les confondre.

Mots clés : multilingue, emprunt, alternance codique, interlocuteurs lettrés, phénomènes linguistiques

Abstract: -The Republic of Benin and the Federal Republic of Nigeria are two multilingual countries. Those two countries are brothers not only by their geographical position, but also through their peoples. Both countries have been colonized by two different European countries, namely and respectively by the French and the English peoples. That added to the many existing languages the one of the colonizer which therefore became the official language with a particular status. That status made French the lingua franca in Benin and English the lingua franca in Nigeria, among the different ethnic groups of the two countries. Today, the use of French among Baatombu speakers in Benin and the use of English among Baatombu speakers in Nigeria, has become a common phenomenon in each of the two countries, as each of the two languages stands a language giving access to upper social classes, a status that gives them high standing prestige. The direct consequence of that hegemonic position of French and English is the mutual influence expressed through code-switching that some literate speakers awkwardly hide behind the linguistic phenomenon called borrowing. Code-switching and borrowing are two linguistic phenomena that occur under some circumstances. The present study attempts to identify the circumstances under which they occur as well as it proposes to show the circumstances that lead speakers to confuse them.
\end{abstract}

Key words: multilingual, borrowing, code-switching, literate speakers, linguistic phenomena.

\section{INTRODUCTION}

Some linguistic phenomena occur in the daily use of language in conveying messages accordingly. Those phenomena are almost natural, though they do not occur under the same circumstances. Their occurrence, mainly the co-occurrence of some of them, leads to confusion, not in use, but in consideration. In this study, I would like to discuss two of them: code-switching and borrowing. Code-switching is the alternative use of words and even phrases, by multilingual speakers, from one language to the grammatical frames of another language. As for borrowing, it is the use of words or phrases from one language into another language as part of the latter's lexicon. Both phenomena have to do with material use from a language into another though they are not the same thing. I intend to identify the different circumstances under which they take place and the context of their difference. Hence, the study starts with the sociolinguistic backgrounds of the languages at stake and carries on with the circumstances of occurrence and ends up with the context that shows the difference between code-switching and borrowing. 


\section{SOCIOLINGUISTIC BACKGROUND OF BAATONUM,} ENGLISH AND FRENCH.

\subsection{Baatonum}

Baatonum is a Gur language spoken mainly in north Benin and in Kwara State in Nigeria. Baatombu, the people speaking Baatonum, are also found in other parts of the countries due to migration. Today, many reasons justify the presence of Baatombu in other cities where the use of French (in Benin), the use of English (in Nigeria) is almost the condition to share social life. The main reasons are economic, educational and professional. Those opportunities brought French and English to become the most important medium of their daily conversations.

\subsection{French and English}

Slavery and later on colonization brought French and English in the linguistic sphere of the colonized territories. In 1960, with the independences, French and English have become the official languages respectively in Benin and Nigeria. In Benin, the different constitutions state the official character of French in any formal administrative circumstances and in education. The same must be true in Nigeria where considerable effort is made in the domain of local language transcription and use in specific contexts.If local languages make their way towards a massive use in most of the media, mainly radio and television, French and English still have the lion's share in newspapers in the two countries in which the strength of French and English respectively is not related to demographic considerations but rather to the basic functions they play. Today, the increase, at least, in spoken French and spoken English can be justified by the fact that success, not only in school, but also in general social life, depends on the mastery of French in Benin, or the mastery of English in Nigeria. I can even add that the mastery of French in Nigeria, or the mastery of English in Benin is an asset for applicants to specific jobs. Those languages have become status measuring tools and virtual identity card for the speakers. A French and Ewe speaker and an English and Ewe speaker going for instance to Ghana from Togo or coming back from Ghana to Togo undergo different types of border control, depending on the place of the check point at Aflao Border. Their common Ewe does not indicate their provenance. Above all, the prestigious status that English and French enjoy in Nigeria and Benin has casted citizens in the mould of becoming people of prestige through the mastery of French or English. This run up to prestige constitutes the gate that opens to linguistic phenomena in the daily use of all the encountered languages concerned in the present study.

\section{Sociolinguistic factors that trigger borrowing and code-switching}

\subsection{Borrowing}

Borrowing is a linguistic phenomenon that occurs even in formal occasions. The phenomenon is at two levels in language use. Borrowing occurs in speaking as well as in writing context. Borrowing is most formally used in writing. Anyway, a determined list of words can be accepted through their presence in the dictionaries of the borrower, though a non-exhausted list can actually be used in a target language. For instance, English words or phrases like "week-end", "finish", "mail" can be found in French dictionaries as accepted borrowed words, the same for French words like "fiancé (e)", "machine" in English dictionaries. However, the phenomenon is far from being canalized in actual use of any of the languages for, the speaker feels free in the expression of his/her message. The main factors that traditionally trigger borrowing are lexical concision, personal convenience and, to some extent, lexical shortage.

\subsubsection{Lexical concision}

French and English speakers as any other speakers of the existing languages are accustomed to borrowing phenomenon. One language user, though the source language may have a corresponding word, would prefer use borrowing to have a word that gives the concision and simplicity in a context. For instance, the English word "finish" is preferred to the French word "final". A French speaker prefers saying "au finish" instead of "au final". In the same way, the acronym "SMS" is more often used than the French coined word "texto". Coining effort has been deployed by the French academy, creating new words to replace the English words borrowed like "courriel" for "e-mail", "fin de semaine" for "week-end". This effort of coinage has brought in a new factor triggering borrowing. Personal convenience borrowing occurs where there are corresponding words and phrases that have been invented. Lexical shortage is another factor that triggers borrowing.

\subsubsection{Lexical shortage}

The lack of words to express realities is another factor that leads multilingual speakers to borrow words from one of their spoken languages into another. In considering French and English, few examples can be given here. In French, the words "fiancé" and "fiancée" designate respectively the man that a woman is engaged to, and the woman that a man is engaged to. To my knowledge, no corresponding words to them in English. Thus, the two words are borrowed from French into English. A second example is the word "machine" in French that 
means a piece of equipment with moving parts that is designed to do a particular job. Other words of the same group are whether modified in their spelling like "machete" for "machette" or their pronunciation like "machination", though the fricative / / is observed. A third example in the domain of cooking is the word "fricassée", designating a hot dish made of small pieces of meat and vegetables in a white sauce. A specific type of borrowing is known as "literal translation" or "calque". The literal translation is used in the target language. For example, the English for "gratte-ciel" is "skyscraper", a reorganization of the literal translation "scrapesky". Borrowing is a linguistic phenomenon with a higher degree of formality than code-switching.

\subsection{Code-switching}

Many factors trigger code switching. Some of the factors are linguistic, while others are extralinguistic. Linguistic factors are related to the bilingual speaker him/herself and the languages at his/her disposal for the interaction. Another linguistic factor is what Kachru (1986), cited by Essizewa (2011), refers to as 'cline of bilinguality', that is, the degree of proficiency that bilinguals have in each of their languages of interaction.

Extralinguistic factors include the participants (i.e. different people engaged in the interaction), the topic, (i.e. the subject of discussion), and, more importantly, the setting (the place where the interaction is taking place (home, work, school yard, market, etc.). Jacobson (1979) refers to the factors, participants, topic and setting as "the social situation".In Baatombu society, respect and deference are religiously observed through physical behaviour and acts among which I can mention bowing when greeting elder people, taking off sandals when greeting or entering elder people's room and the choice of the diction when engaged in a discussion with elder people. Let's signal that there is no polite use of plural pronoun for a person to show respect. In such a society, code-switching is a matter of capacity to speak languages concerned in an area. As a consequence, I agree with Jacobson (1979) cited by Kamwangamalu (1989), then by Essizewa (2011) when he wrote that the appropriateness of code-switching "depends on the appraisal on the situation because, if the interlocutors are not those with whom one would engage in code-switching, if the topic is too formal for such a strategy, and if the intent is not one of relaxed communication, no code-switching is likely to occur." However, the pride of the Baatombu, in the will of mentioning their identity, can lead them to code-switch, even in formal occasions, though they may come back to the phrase code-switched in the official language concerned.The formality of the subject matter of a discussion among Baatombu does not alone inhibit code switching in most cases in the Baatombu area. It is known that after the setting of the colonizer's language with all the prestige that accompanies it, second languages are not used in administration and schools, but rather largely used at any other occasion, mainly occasions when no official minute or report is expected. Hence, in the area of the study, Baatonum - French and Baatonum - English are the combinations of code-switching that occur more in informal circumstances than in formal ones. The formality is therefore coupled with the demand of written paper that gives an account of not only the steps but also the different interventions. In such cases, interlocutors avoid code-switching in order to prevent misinterpretation of their speeches.During my investigations about the topic of the present study, I mainly worked through observation and interviews. The different habits observed and the different opinions gathered indicated some circumstances under which code-switching occurs not without the sociolinguistic factors mentioned above and that can be summed up as follows:

- Contact between official language and mother tongue;

- Instruction in the official language;

- informality of the discourse;

- Lexical shortage of the interlocutors;

- Pride of identity expression (linguistic selfishness);

- Relationships of the participants;

- Difficulties in verb tense agreement.

\subsubsection{Contact between official language and local language}

In Benin in general, there are many local languages spoken here and there according to the ethnic groups in presence. In some areas, more than one language exists in some villages. In some villages of the area of the present study, three ethnic groups share same villages, like Kalale, Bouka in the District of Kalale where Baatonum, Fulfulde and Boo co-exist. But there is no possible code-switching between any two of them. The same is true for their homologue villages in Kwara state and even the River state in Nigeria. But, as soon as French or English are at stake, code-switching occurs. Though those local languages are in contact before the arrival of French in Benin and English in Nigeria, and though no evidence of genetic relation among them, as the case with French or English, two bilingual speakers of Baatonum and Fulfulde or Baatonum and Boo show no sign of code-switching. So the contact with a colonizer's language is determinant in the occurrence of codeswitching. This situation can be explained by the fact that, though the colonizer has left, he left his language with a prestige position that enhances its role of hyphen. The more you speak the colonizer's language, the quickest you are taken as embodying modernity and susceptible of being consulted. 
Though Essizewa $(2006,2011)$ found that Kabiye and Ewe code-switch, I think that with no prestige position for one of the languages in contact, there is no code-switching. This means that for the case of Kabiye-Ewe, whether Kabiye is prestigious or Ewe is. What is obvious is that the two languages are taught in Togo, and they are the most spoken in the country, Ewe in the south and Kabiye in the north. So, code-switching may be for the Togolese case a sign of complete integrative social ascension of the speakers. But no such case is possible for the case of the area of the present study. A phenomenon is nevertheless observed and it is worth mentioning it here. A discussion between two Baatombu speakers with code-switching may continue though a third interlocutor who joins them does not speak French. The first interlocutors can code-switch when they address each other, and they can stop code-switching when they address the new comer. Such cases occur when the new comer asks or offers services or information. The degree of instruction of the new comer can allow him to also carry on with code-switching.

\subsubsection{Instruction in the official language}

The degree of instruction combined with the general linguistic background is a key factor in the occurrence of code-switching between speakers of the official language and a mother tongue. It is obvious that one cannot code-switch a language for which he knows nothing. So, the condition is being able to utter the minimum in it. Hence, the frequency of code-switching is related to the degree of linguistic competence of an interlocutor and then to the interlocutors engaged. Here, an aspect is to be signaled. It has to do with the concept of "schema". A schema is a cerebral disk that keeps information, pictures, words, phrases, signs, sounds etc. relatively ready for use. Everything that regularly comes back in the speaker's mind, words and phrases for instance, is kept in the schemata. The observation for that aspect led to the conclusion that a long sojourn abroad, can lead the speaker to have the official language closer. In such a case, the interlocutor may very often code switch with the predominance of the official language.

\subsubsection{Informality of the discourse}

The word discourse is used here to mean any language event in which participants are orally engaged. Sometimes, the context of a discourse can apparently sound informal and be reinforced to become more formal. I took part to a meeting of a local association for the development of a village in the area of the study, namely N'Dali in Borgou department in the north of Benin. The different speeches at the opening of the Assembly held in French, with a protocol intervening before and after a speech, suffers no code-switching. But, when the local authorities retired in order to leave the participants start the actual meeting, during the short dialogue that took place when the authorities were accompanied to their car by some of the members of the committee of organization, code-switching occurs. Here is a piece of that conversation:

Mayor: 'Nen programme yaku na san surchargé, je resterais un peu plus longtemps pour suivre les débats'.

Head of the committee : 'Ah oui, kaa deema participants ba koo tii win plus'.

(Mayor: 'Si mon programme n'était pas surchargé, je ....'; Head of the committee : 'Ah oui, votre présence amènerait les participants à plus d'effort').

The speeches were held in a formal context; that is the reason why there was no insertion of code-switching. But, informality starts with the exchange of some words before the departure of the authorities. Also, once in the workshops of the assembly, one could here again code-switching from time to time. As Forson (1979), cited by Essizewa (2011), remarks it, the degree of formality of the discourse is an important factor in the occurrence of code-switching. But, I observed that, in a given social situation with a given level of formality, cultural and traditional contributions show more formality not for the sake of the situation, but rather the character of the contribution. The traditional authority that also came to the opening of the above mentioned assembly took the floor for a prayer. Though a retired, he used no code switching during his prayer:

'Bona kecri u swaa gbii, oru yeru u su n yonre, I menno ge koo, nim mu n do, dan ya n do; wiru tu ku goo so, nuki yu ku goo tinma; ...'

Moreover, Nikki, the setting of the present study, is the venue of the annual traditional feast of the Baatombu called "Gaani" the celebration of which goes through some rites. Some of the kings have been civil servants, like Sero Tassou who was a police agent. No code-switching occurs during the rites. Each rite is performed in Baatonum. Once again, the degree of formality is determinant in the occurrence of code-switching. Lexical difficulties can also trigger code-switching.

\subsubsection{Lexical shortage}

The phenomenon of code-switching is related to many factors that I am trying to identify from the different observations and interviews carried out in the area of Nikki in the north of Benin. Some of the factors tend to hide others like the lexical insufficiency depending on the field of the discourse. The topic may demand words and phrases which are not in the fresh schemata of the interlocutors and which are indispensable for its development. The dominance of Baatonum or French in code-switching depends, once again, on the topic. For 
instance, a topic about a bicycle and its different part is more likely to have the dominance of the official language since the bicycle is a western invention. Even if the Baatombu have a high capacity of finding correspondent to western inventions, it is not easy to do it for parts of a whole for which a correspondent is created. For example, the word bicycle is called "sii duma", that is "iron horse". So, the word "sii duma" is used currently and any code switching from Baatonum to French is considered to be related to other factors, but not lexical shortage. But, a discourse about parts of the bicycle cannot be carried in Baatonum without codeswitching. The words like hub, spoke, rim, tire, tube, hand bar, brake etc. do not exist in Baatonum. Any topic about the description of the bicycle will be developed with the occurrence of code-switching. In the opposite situation, it is possible to have topics in which the interlocutors have lexical difficulties in the official language. The social situations of culture and tradition are examples of lexical shortage in the official language. That factor is slightly different from the level of instruction of the interlocutors.In fact, students may be more likely to code-switch during a discussion among themselves depending on the form in which they are. The conventions like symbols, geometric figures, diagrams in mathematics will come easily in French or English in a discussion among students. But, the language handling about them is the moment when they often switch. The following example is a discussion between two classmates after a lesson of mathematics on triangles:

Student1: 'Nan mati yen yaasi wa gison ni, similitidu yen gari saa kua mi, il a beaucoup plus parlé de Thalès, non teera u ma n Pitagos sia, en tout cas, c'est pas clair.'

Student2: 'Nonnn, on a parlé de triangles semblables, mia propriétés de Thalès nu somburu mo. et c'est le rapport de similitude qui concerne ces propriétés. U de ne wa quand il s'agit de triangle rectangle, que la relation de Pythagore est évoquée, su ka kpin su calcul des côtés koo'.

Through the discussion, it has been clear to me that student1 did not understand the lesson and tried to have more explanation without asking directly a question about his objective in coming back on the class situation:

'Je n'ai pas compris le cours de maths d'aujourd'hui; la similitude don't il (le professeur) a parlé, il y a mis l'accent sur Thalès, il n'a évoqué Pythagore qu'une seule fois, ce n'est pas clair pour moi.'

But, student 2 understood him and brought explanation, not without code-switching:

'Non, on a parlé de triangles semblables; c'est là où interviennent les propriétés de Thalès; et c'est le rapport de similitude qui est concerné par ces propriétés. Il a seulement dit que quand il s'agit de triangles rectangles, la relation de Pythagore est évoquée afin de pouvoir calculer les côtés.'

Each of the factors that trigger code-switching can be justified to some degree as many factor scan meet in a single social situation. But, it is difficult to identify in such a case a single factor that conditions code-switching in that determined social situation. It is for this reason that some people I interviewed in Parakou evoked, among other factors, "linguistic selfishness" of the interlocutors.

\subsubsection{Pride of identity expression/linguistic selfishness}

'Linguistic selfishness', as one of my interviewees called it, is in fact the pride that interlocutors feel through code-switching just because they want to indicate their cultural identity. That interviewee thinks that, even if other factors contribute to code-switching, the one he evokes plays its partition. An anecdote was narrated as an example. A Beninese student in Saudia was in the group of interpreters that were invited by the embassy there for an audience accorded to the presidential delegation in 2011. The student recognized a minister from his home town and was eager to make himself noticed by that minister. In greeting the members of the presidential delegation, he decided, at the level of that minister to code-switch. So, this greeting with codeswitching is simply drawing the minister's attention; and he actually drew the student aside for further information about his being there. The formality of the context did not prevent the student from code-switching.

\subsubsection{Relationship between interlocutors}

The relationship between two or more interlocutors is also a factor that brings speakers to codeswitching. The problem of proficiency in the official language does not to be mixed with the present factor which is concerned only with the degree of familiarity between the interlocutors. That is, two proficient interlocutors may code-switch according to whether they have just met for the first time or very familiar one to the other. In working context, the boss and an employee are less likely to cod-switch, unless the boss starts on a given purpose whereas two colleagues of the same status in the same service may be more likely to code-switch. In Baatonum community, there is a kind of traditional hierarchy which is not a hierarchy in the meaning of the word, though there is sense in the reality. In fact, the Baatombu consider two levels of hierarchy in the society: the 'Wure' and the 'Kpai', apart from the communal hierarchy in any human society. The Baatonu society is patrilineal and as such, if your father is 'Wure', this means that your paternal grandfather is 'Kpai' and that you are 'Kpai' or your father is 'Kpai', then, your grandfather and you are 'Wure'. This means that grandparents and grandsons match. As a consequence, a grandson is more likely to code-switch with his grandfather than with his father. This is only true for only a few young Baatombu, since the colonial school reached the Baatombu area 
less than a century ago. However, the notion of relatives or extended family in Africa tries to offer opportunity to today young Baatombu to have almost learned-grandparents with whom they may code-switch.

In the communal societal hierarchy, nevertheless, code-switching is less likely to occur in a discussion between a younger and an elder, unless the elder initiates it for a reason or another. Any initiation of code-switching by the younger is automatically considered as boasting and then irreverence. Another factor that triggers codeswitching is the problem of verb tense agreement.

\subsubsection{Difficulty in verb tense agreement}

Baatonum has almost all the verb-tense distinctions that students learn. However, generally, past, present, future, imperative and conditional tenses and modes are used in Baatonum grammar. In Baatonum, the subjunctive mode is relatively easy to use since the difference between subjunctive present and subjunctive past, though existing, is less mentioned in use. In French the subjunctive is supposed to be the most difficult mode in verb management because the use of its different tenses is conditioned in most cases to the tense of the main verb of the sentence of which the subjunctive appears in the subordinate clause. In French, four tenses are distinguished in the subjunctive mode: "présent", "passé", "imparfait" and "plus-que-parfait". In tense agreement, the indicative simple present goes with the subjunctive present; indicative "imparfait" goes with subjunctive "imparfait". The problem is that in some contexts, both indicative tenses go respectively with the subjunctive past, and with the subjunctive plus-que-parfait. As such, the speakers must know when to use this or that subjunctive tense to have the right tense agreement. It is there that Baatombu bilingual speakers much codeswitch, mainly students. It is easier for a student to say in French "J'exige qu'il vienne demain" than "J'exigeais qu'il vînt demain", or "J'exige que tu aies terminé avant midi", or "J'exigeais que tu eusses terminé à 11 heures".

For such verb tense agreement difficulties, code-switching occurs as a way to sway the difficulties in order to be as fluent as possible in the discussion. For the above examples, one is more likely to hear:

"J'exige ù na sia" and "J'exige a kpee midi yu sere so" though we should normally have:

- "J'exige qu'il vienne demain" = "J’exige ù na sia".

- "J'exigeais qu'il vînt demain" = "J'exigeais u n ne sia".

- "J'exige que tu aies terminé" = "J'exige a n kpaa".

- "J'exigeais que tu eusses terminé" = "J'exigeais a n kpaa".

In Baatonum, the subjunctive present is used for all the subjunctive tenses existing in French, the reason why code-switching occurs easily there to solve, I believe, the problem of tense agreement. Another remark is that, tense mistakes and errors are not considered in spoken Baatonum. It is a factor that gives ease in using wrong tense through code-switching.In the list of factors evoked that trigger code-switching, it is possible to have omitted some. However, I think that I have mentioned the most obvious ones. Nevertheless, I must confess that any single factor is not totally sufficient in the triggering of the linguistic phenomenon known as code-switching: language contact, degree of formality of the discourse, participants' relationship, pride of identity expression, instruction in the official language, lexical shortage, and verb tense agreement difficulties, combine to trigger code switching. Borrowing and code-switching are linguistic phenomena having few common characteristics.

\section{DIFFERENCES BETWEEN BORROWING AND CODE-SWITCHING}

Both phenomena are related to language contact and depend on the choice of the speaker, that is, a speaker is free to borrow a word or a phrase as well as he/she is three to code-switch when engaged in a discussion. However, participants are more limited in borrowing than in code-switching, since borrowing is more formal and linguistically controlled than code-switching which follows no rule and has no standard structure or form. Anyway, no formal material support for code-switching whereas borrowing can be found in formal language whether written or spoken, in dictionaries and in encyclopedias. The key difference between borrowing and code-switching is that code-switching is totally informal and occurs only in oral context. In each language, an official list of words borrowed is relatively known and a speaker can borrow into a single text from many languages, up to the interlocutor or a reader to check the meaning of borrowed words. As for codeswitching, it occurs only in cases bilingual or multilingual participants are engaged in a discussion.

\section{CONCLUSION}

Linguistic phenomena that occur under various societal circumstances are considered normal for linguists whose aim is to be able to study them and give relatively objective explanations or justifications. The present study is an example which has aimed to study the factors that trigger borrowing and code-switching in the north-eastern border of Benin and Kwara State in the Federal Republic of Nigeria between Baatonum and French, and Baatonum and English. Among the many factors that help the phenomena occur are language contact and lexical shortage which are common to borrowing and code-switching. Other factors are proper to 
code-switching like the degree of formality of the discourse and some problems of proficiency of the participants engaged in a discussion.It has been found that borrowing is more formal than code-switching, since it can be spoken or written, and official documents can indicate words borrowed. Code-switching is for the time being oral and randomly used. However, both phenomena signal language existence and language contact.

\section{BIBLIOGRAPHY}

[1] Essizewa, E. K. (2006a). Sociolinguistic Aspects of Kabiye-Ewe Bilingualism in Togo. Ph. D Dissertation, New York University.

[2] Essizewa, K. E. (2009). Kabiye-French code-switching: a case study of student at Université de Lomé. In Geste et Voix, Revue scientifique, Université d'Abomey-Calavi.

[3] Essizewa, K. (2011). Sociolinguistic Factors for Code-Switching in a Bilingual Community: a case study of Kabiye-French Bilingual Speakers. In Particip'Action, Vol.3, N¹, Revue Scientifique, Universitéde Lomé.

[4] Forson, B. (1979).Code-switching in Akan-English Bilingualism. Ph.D. Dissertation, University of California, Los Angelos.

[5] Jakobson, R. (1979). Code-switching in South Texas. In Journal of the Linguistic Association of the Southwest, vol.3.

[6] Kachru, B. (1986). The Alchemy of English, Pergamon Press, Oxford.

[7] Kamwangamalu, M. N. (1989). Code-mixing across Cultures: Structure, Functions, and Constraints. Ph.D. Dissertation, University of Illinois at Urbana-Champaign, Illinois.

[8] Yule, G. (1985). The Study of Language. Cambridge University Press, Cambridge. (Low Price Edition, second edition, 1996). 